\title{
Research on the Dynamic Capabilities of the Enterprise Based on Knowledge Management
}

\author{
Wang Zhanying \\ Wuhan University of Technology, \\ Wuhan, china 430063
}

\begin{abstract}
Knowledge management through knowledge sharing and the learning organization can strengthen the enterprise's adaptability and creativity in the dynamic environment. And the knowledge management can promote the culture of the dynamic core Capabilities, help to achieve the sustainable development of enterprises. For Chinese enterprises, some problems still exist about the culture of the dynamic core competence. The paper in order to promote the culture of dynamic capabilities, from changing the management philosophy, promoting organizational change, information management, and learning organization ways to talk over the ways about the culture of the dynamic core competence.
\end{abstract}

Keywords----Knowledge Management; Dynamic capabilities of enterprises; Sustainable development

With the continuous deepening about the enterprise knowledge management, Chinese knowledge management has a big development, including the kernel knowledge management and joint knowledge management. Through the human resource management, organizational design, corporate culture construction and IT management, to strengthen the enterprise's management on dominant knowledge and tacit knowledge, in order to achieve the sharing, the introduction, the innovation and the spillovers of the enterprise knowledge, and then, contributing to construct the core competitiveness of enterprises. For the Chinese enterprise, dynamic ability and competitiveness is more and more difficult to cultivate in the deterioration of the international environment and industrial transfer environment. Therefore, through Knowledge management to promote the culture of the dynamic core capabilities, becoming the main way to strengthen the core competitiveness of construction and to increase market share.

\section{THE PROBLEMS OF IMPLEMENTING KNOWLEDGE MANAGEMENT}

For the external environment, in the process of implementing knowledge management to promote the culture of the dynamic core capability, Chinese enterprises always face some main problems, including:

\section{A. Weak awareness of enterprise knowledge management}

At present, the biggest obstacle to implement knowledge management is management concepts lag.
First, concept of the knowledge management is lag. Knowledge management is can't create significant economic immediately, but enterprises are still mired in traditional management, not yet aware of the necessity and urgency to implement the knowledge management, and even corporate managers lack a basic understanding of the concept of knowledge management, lack of a systematic understanding of full implementation of knowledge management.

Second, lack the necessary fundamentals. If the lack of these basic elements, such as human, financial, material and technical, then, to establish, to improve and to implement enterprises' knowledge management is very difficult. What's more, enterprises are still accustomed to under the traditional system management mode, seniority, nepotism is still more serious, leading many young and Innovative people are not playing their strengths, and wasting many manpower and knowledge resources.

Third, lack an effective system. Institutional arrangements unreasonable, leading to the enterprise management system running slow, unable to optimize the allocation of material resources, and then, insulting knowledge management can't be implemented.

At last, lack of the system knowledge strategic management model. Many enterprises have not formulated the effective knowledge management strategy, and have no the department and the competent to implement the knowledge management. Which resulting in the transmission of information of the enterprise is still in its infancy, and the lack of support of advanced knowledge management tools, even some few enterprises have no the basic intranet established.

\section{B. Lack of shared and exchanged corporate culture}

The formation, transfer and retention of the corporate knowledge is rooted in the organizational environment, the characteristics of the organizational environment will affect the growth and development of knowledge. For the enterprise knowledge activities, the corporate culture as the specific organizational environment playing an important role in the process of the knowledge-intensive and innovative. So, positive corporate culture can encourage the creation of new knowledge, helping to format the mutual trust and the unity of value. Also, the actions conducive to establish the atmosphere of knowledge sharing and exchange, accelerate the knowledge innovation. 
However, many Chinese enterprises formed conservative, boring, lack of dynamic corporate culture under the traditional system, which have seriously affected the enterprises' knowledge management activities.

At the same time, Chinese corporate culture is only a form; don't pay attention to the establishment of encouraging cooperation, transform and innovative about the corporate culture.

\section{Lack of knowledge innovation capability}

In order to accelerate the pace of the enterprises' development, enterprises are often willing to pursue low-cost. But, the low cost insulting the neglect of the investment on the research and development, knowledge creation. Therefore, to enhance enterprise knowledge management must focus on the ability of the enterprise knowledge innovation.

For Chinese enterprises, some problems exist in the knowledge innovation. Including, 1)the operators do not pay attention to the creation of knowledge, neglect of investment in knowledge innovation;2)lack of the learning atmosphere, employees lack of the chance knowledge innovation;3)the polarization is seriously, there is no ability to conduct information transformation and knowledge-based;4)the competition is underpowered, insulting enterprises into indolent the knowledge, innovation and management.

\section{$D$. The low level of the enterprise information}

Knowledge management can't do well without the support of the IT; the level largely depends on the degree of information construction. Enterprise information technology is a process, refers to the use of modern information technology, through the deepening development and widespread use for the information, to improve the production, operation, management, efficiency and level of decision-making constantly, thereby increasing economic efficiency and competitiveness of enterprises of information resources.

There is still a big gap on the information scale, the level and the overall level for our enterprise, so there is a great obstacle to the Chinese enterprises in the implementation of knowledge management.

\section{THE ROLE OF KNOWLEDGE MANAGEMENT IN PROMOTING TO CULTURE ENTERPRISES' DYNAMIC CAPABILITY}

In the process of the operation of the business organization, knowledge can combine the corporate and its activity factors, and then form the dynamic capability of enterprises.

\section{A. Integrating information to reduce costs}

In a way, the collecting speed and the processing level of the information, the ability of information into knowledge, and the ability of staff use the information into internalization, which determine the enterprise seize opportunities in the rapidly changing market. Therefore, knowledge can play an important role through integrating analysis and sorting in the enterprise.

Personal knowledge and business knowledge must be integrated and consolidated through the database of knowledge, talent database, expert systems, and market information database in the enterprise. And then, the subtle patterns of behavior and the habits processes will be better educated, so that it can spread to the extent permitted promotion. So that you can save the search costs and the cost of trial and error, to gain advantage in time and material relative to the market competitors.

\section{B. Creating a problem-solving path to improve efficiency}

Through the creation of a knowledge map, can provide the smooth settlement for any problem in the enterprise and improve the efficiency of the problems greatly. The efficiency of each firm to handle the normal things is not much difference, but the sudden event processing efficiency is the key to reflect the corporate capacity, this is precisely where dynamic enterprise capabilities.

When the corporate affairs encounter problems, using knowledge map can make the parties expressly corresponding resources, departments, staff and solutions, so that the entire problem-solving process to start and eventually be resolved in accordance with a standardized procedure. In addition, the problem has been resolved, need to login the case into case base timely, so that can solve the similar incidents speedily.

\section{Optimizing talent to play professional advantages}

The person is the center of the medium of knowledge transfer and knowledge creation. The role of the knowledge is also a process of the employees learn to manage and play professional advantage. Therefore, the key is, how to exploit the staffs' knowledge in their mind to make it into the collective wisdom, and to improve the enterprise's rapid response capability and resilience; how to through the system of classification, finishing into a powerful knowledge base and to become employees information base by retrieving; how to ensure the organization to learn, through the attack by different personal minds to gain the collective experience, in order to deal everything by playing the strength of the team and improve the speed of the corporate response.

\section{Optimizing the organization to raise overall efficiency}

The organization is not only affecting the dissemination of knowledge, but also determining the speed of the transmission of the information. In turn, the knowledge also has a powerful impact on the structure and efficiency of the organization. At first, the paths of the knowledge propagation and the processes of the knowledge management play a great role on promoting the organization change; Second, under the impact of the 
knowledge flow, the overall behavior will change, including the organizational structure and management level, management range design. In such a context, enterprise will operate in accordance with a whole new way. And then, enterprises as the coordinating for the knowledge, the knowledge as the power driven the enterprises run.

\section{THE EFFECTIVE PATH BASED ON KNOWLEDGE MANAGEMENT TO CULTURE THE DYNAMIC CAPABILITIES}

\section{A. Changing concept to establish the necessary information systems}

The most basic role of knowledge management is to establish the rapid transfer channel for the enterprise information, to have a fast processing power in the business operations. In the other words, for deep-level mining knowledge management, and then analyzes the current, historical operating data and environmental data to obtain useful information for decision-making, in order to provide enterprises with a fast, accurate and convenient decision support. Further speaking, is to achieve intelligent operations. The creation of the intelligent operations is based on intelligence facilities, using intelligent analysis tools and analytical artifice to observation of the internal and external environment closely, and adjusting constantly and warning timely based on the observations. At last, guiding business operations and improve the speed of business operations.

In order to improve the level of business intelligence operations, the enterprise need to improve the conditions and facilities, such as expert systems, decision support systems, customer data warehouse, knowledge of data warehousing, information portal. These systems not only improve the internal management level, but also enhance the enterprise's rapid response and management capabilities. Among them, the expert system is the core of knowledge transfer and knowledge creation, is the necessary condition of knowledge management; Data warehouse is not a simple data accumulation, but to extract data from a large capacity transactional database, and clean-up, converted to a new storage format, providing the main platform for the enterprise knowledge management; The decision support system as a computer system is based on the types of data in daily business processing, using database technology or business intelligence systems to analysis or prediction the business data, to help business leaders making decisions on the problems, such as, business developments and business strategy of the enterprise market.

\section{B. Improving the knowledge management system}

Generally speaking, knowledge management including four links, such as variation, internal selection, dissemination and maintain. Among them, variation is the starting point, and providing direction the ability to evolutionary; internal selection determines the quality of the evolution of dynamic capabilities, because only the wise and prudent choice can make capacity in the appropriate fields; dissemination is an important part that can guide the knowledge play a role in the company's operations; maintain is a key link of the convention fixed for the ability. Of dynamic capability is only through the combined effects of the four areas, can play a role exactly. Therefore, knowledge management must be implemented rigorously and creatively based on the way of these four areas required for.

\section{Establishing a system innovation system}

Fundamentally speaking, knowledge management is innovation management. The connotation of innovation includes the concept of innovation, technological innovation, system innovation, management innovation. Among, technological innovation is the main form of enterprise innovation, and the direct impact of the enterprises' competitiveness. Therefore, to establish a sound innovation system is the effective way, which can strengthen enterprise knowledge management and promote the culture of the dynamic capability of enterprises.

First, strengthen the power of research, development and marketing. Each enterprise should have its own R \& D institutions, especially for large enterprises, which should seize the opportunities of the national science and technology system, to absorb the original state-owned research institutions, and then change them into the enterprise Research Institute. In addition, enterprise should recruit a number of scientific and technical personnel, and strengthen the collaboration and cooperation with higher levels of tertiary institutions and the industry, research institutes, in order to raise the level of their own research and development.

Second, establish an effective incentive mechanism. Effective incentive mechanism is an important guarantee for the promotion of innovation. For the invention of the scientific and technical personnel, innovative incentives including cash incentive, equity incentive and awards.

\section{CONCLUSION}

In the era of knowledge economy, enterprise knowledge management is an important enterprise management theory and methods, which will promote many management theories to the in-depth development. Re-transform the enterprise information management theory, to emphases the application of information technology. According to improve the knowledge management system, change concepts, innovate mechanisms and the necessary information systems will advance the nurturing and development of dynamic capabilities, so as to realize the sustainable growth of the enterprises. 


\section{REFERENCES}

[1]Ke Xing. Organizational Evolution Path Dependency Analysis[J]. Science \& Technology Progress and Policy, 2006 (2)

[2]Dai Wanwen, Zhao Shuming, Jiang Jianwu,Steve F Foster. Complex Systems, Knowledge Management and Organizational Learning Process Dynamic Model[J]. China Soft Science, 2006 (6)

[3]Wang Fanghua. Management Theory[M]. Taiyuan, Shanxi University Press, 2009

[4]Wu Jiapei. Knowledge Management and Information Management[J]. China Reform Newspaper, 2008 